\title{
Indicators of the risk mechanics for Class-I and Class-II amalgam and composite resin restorations
}

\author{
Eduardo Fernández ${ }^{1}$, Erik Dreyer Arroyo ${ }^{2}$, Claudia Letelier Pardo ${ }^{1}$, Osmir Batista Oliveira Junior $^{3}$, \\ Gustavo Moncada Cortés ${ }^{1}$, Javier Martín Casielles ${ }^{1}$ \\ ${ }^{1}$ University of Chile, Department of Restorative Dentistry, Independencia, Santiago, Chile \\ 2University of Chile, Department of Conservative Dentistry, Independencia, Santiago, Chile \\ ${ }^{3}$ Universidade Estadual Paulista - UNESP, Araraquara Dental School, Department of Restorative Dentistry, Araraquara, SP, Brazil
}

\begin{abstract}
Aim: To determine indicators of prognosis for mechanical risks of amalgam and composite resin restorations in permanent teeth. Methods: Thirty-nine adult patients with direct clinical, photographic, radiographic and model examinations. A total of 256 restorations were classified as "not satisfactory," with Bravo or Charlie values according to the modified Ryge /USPHS criteria. The total " $n$ " was divided into Bravo and Charlie groups according to the value obtained in the "marginal adaptation" parameter. Each of the groups was sub-divided by the type of material (amalgam and composite resins) and the class: occlusal (O) and proximal (MOD). Results: Comparing the Bravo and Charlie groups, the statistically significant indicators were: the mesiodistal dimension $(p=0.037)$, the distal isthmus $(p<0.05)$, the average of the isthmuses $(p<0.05)$, the distal $(p<0.05)$ cavity depth, and the average depth of the MOD $(p<0.05)$ cavities. It was concluded that the type and the class of the restoration are not indicators for sampling. Conclusions: With regard to the design of the cavity preparation, the valid mechanical risk indicators include the mesiodistal dimension, the distal isthmus, the average of the isthmuses, the depth of the distal cavity and the average depth of the MOD cavities. A simple clinical assessment does not provide sufficient information to establish the indicators for mechanical failure risk of restorations.
\end{abstract}

Keywords: risk management; composite resins; dental amalgam.

\section{Introduction}

Restorations exist in a septic environment and are functionally tested during chewing, a series of mechanical loads and flexural compressions that are increased in magnitude if the patient presents bruxism or has a reduced number of teeth ${ }^{1}$.

Received for publication: April 24, 2014 Accepted: June 10, 2014

Correspondence to: Eduardo Fernández

University of Chile, Director of Department Restorative Dentistry,

Olivos 943 - Independencia - Santiago - Chile

Phone: +56998854770

E-mail: edofdez@yahoo.com
Due to multiple reasons, these restorations may fail and require replacement ${ }^{2-10}$. While treatment variables are often studied, it is necessary to study the causes of failure and within those causes, to search for indicators that can be easily recognized, assessed and compared over time to establish the predictors of mechanical failure risk for the restored teeth.

Among the causes of most important mechanical failures are marginal defects in composite resins restorations. It is important for the assessment of defective restorations to understand how the failure occurs ${ }^{11}$. Despite the development of new materials that compensate phenomena such as the $\mathrm{C}$ factor in operative cavities, 
it is important to understand what would be the main risk indicators to improve proper decisions ${ }^{12}$

The present work aimed to identify the indicators for the prognosis of mechanical risks for unsatisfactory resin restorations in a follow-up. The tested hypothesis was that it is possible to identify mechanical risk indicators of failed defective amalgam and composite resin restorations.

\section{Material and methods}

This study was approved by the Ethics Committee of the Research Office of the Dental School of University of Chile ascribed to PRI-ODO 12-005. All patients signed informed consent forms and completed a registration form.

Thirty-nine adult patients underwent a clinical examination (direct examination), along with photographic, radiographic and model examinations (indirect tests) as proposed by the literature. The clinical examinations were performed using the Ryge/USPHS modified criteria ${ }^{13-14}$ by a previously calibrated operator (Cohen's Kappa $85 \%$ concordance), in which all Class I and II composite resin and amalgam restorations were classified either as "satisfactory" (Alpha) or "not satisfactory" (Bravo and Charlie).

The photographic study consisted of digital photographs (Nikon D100, Tokyo, Japan) of both arches and the individual restored teeth in all patients. The radiological examination consisted of standardized bilateral bitewing radiographs in all patients. The analysis of models consisted of standardized impressions of the arches, obtained at the time of surgery with polyether impression material Impregum Penta Soft (3M ESPE, St Paul, MN, USA), which were later poured with extrahard plaster (Sintec Ltda, Santiago, Chile).

All patients of the Operative Dental Clinic of University of Chile of a period (1 year) $(n=156)$ were randomly selected and enrolled in a representative sample of 39 patients. The total number of failed restorations $(\mathrm{n}=256)$ was divided into two groups, Bravo and Charlie, according to the value obtained in the "marginal adaptation" evaluation by the modified Ryge/USPHS criteria. The following indicators of the prognosis of mechanical risk were evaluated for each restoration in a standardized fashion using previously obtained $\mathrm{x}$-rays and models, as described in the literature ${ }^{1,15}$.

\section{Indicators of the prognosis of mechanical risk}

1. Class of restoration: Occlusal (O), Proximal (P), MesioOcclusal-Distal (MOD) restorations. 2. Type of restorative material: Amalgam or resin composite. 3. Design of the cavity preparation: The size of the restoration as a class was measured on the radiographs and models using a millimeter ruler (Staedtler, Nüremberg, Germany) with $0.5-\mathrm{mm}$ increments. In the models, the mesiodistal dimension, the buccolingual dimension, the mesial isthmus and the distal width were measured. In the radiographs were measured the mesiodistal dimension and the depths of the mesial, occlusal, and distal (MOD) cavities.
All of the collected data were entered into an Excel spreadsheet to be statistically analyzed. The confidence level was set at $p=0.05$. The SSPSv21.0 statistical program (IBM, New York, NY, USA) was used.

\section{Statistical analysis}

The total number of "unsatisfactory" restorations was divided into two groups, Bravo and Charlie, which constituted independent variables, each with different $n$ values. At an early stage, they were compared generally with Student's t-test for the indicators. Then, one-way ANOVA was used to compare the indicators of design in both groups by the type of restoration (amalgam and composite resin), without considering the class. Later, the classes were compared among themselves according to group and class with a Scheffé test.

\section{Results}

\section{General comparison of the Bravo and Charlie groups:}

The statistically significant indicators were: the mesiodistal dimension in both model restorations $(p=0.037)$ and radiographs $(p=0.014)$, the distal isthmus $(p<0.05)$, the average of the isthmuses $(p<0.05)$, the distal cavity depth $(p<0.05)$, and the average of the depths of the MOD cavities $(\mathrm{p}<0.05)$. The data are presented in Table 1 .

\section{Comparison of each class (occlusal, proximal, MOD) by group and type (amalgam and resin)}

The distribution of the sample is presented in Table 2. Using one-way ANOVA, the amalgam and resin restorations were compared by groups (Bravo and Charlie), without comparing their types. The results of this analysis are presented in Tables 3 and 4 .

Table 3 presents that there were significantly different indicators between the composite resin and the amalgam restorations in the Bravo group. Table 4 presents that there were indicators that had statistically significant differences between the composite resin and the amalgam restorations in the Charlie group. The results of the comparison of classes (occlusal, proximal and MOD) by group and type of restoration are presented in Tables 5 and 6 .

Table 5 shows that there were significant differences within the amalgam restorations of the Bravo group (ANOVA and Scheffé test, $\mathrm{p}<0.05)$ for the following indicators: mesiodistal dimension $(p<0.05)$, the average of the isthmuses $(p<0.05)$ and the average of the depths of the MOD cavities $(p<0.05)$. These three indicators were significant in the comparison of types: MOD, proximal occlusal vs. MOD, and proximal occlusal. As shown in the table, the $\mathrm{p}$ values were not significant statistically for the labio-linguo-palatal dimension among the three classes. This demonstrates that, within the resin composite restorations of the Bravo group, 
Table 1. Comparative values (in $\mathrm{mm}$ ) for group indicators regardless of type and class of the restoration.

\begin{tabular}{|c|c|c|c|c|c|c|}
\hline Indicator & Group & $n$ & Average & DS & Means difference & $p$ value \\
\hline \multirow[t]{2}{*}{ Mesiodistal dimension } & Bravo & 178 & 6.355 & 2.337 & 0.663 & 0.037 \\
\hline & Charlie & 78 & 7.018 & 2.308 & & \\
\hline \multirow[t]{2}{*}{ Buccolingual/palatal dimension } & Bravo & 178 & 4.008 & 1.652 & 0.361 & 0.121 \\
\hline & Charlie & 78 & 4.369 & 1.845 & & \\
\hline \multirow[t]{2}{*}{ Mesial isthmus } & Bravo & 178 & 0.992 & 1.689 & 0.393 & 0.098 \\
\hline & Charlie & 78 & 1.305 & 1.862 & & \\
\hline \multirow[t]{2}{*}{ Distal isthmus } & Bravo & 178 & 0.671 & 1.464 & 0.870 & 0.000 \\
\hline & Charlie & 78 & 1.541 & 1.903 & & \\
\hline \multirow[t]{2}{*}{ Average of isthmuses } & Bravo & 178 & 0.831 & 1.219 & 0.631 & 0.000 \\
\hline & Charlie & 78 & 1.463 & 1.230 & & \\
\hline \multirow[t]{2}{*}{ Mesiodistal dimension (bitewing radiograph) } & Bravo & 178 & 6.537 & 2.502 & 0.798 & 0.014 \\
\hline & Charlie & 78 & 7.335 & 2.295 & & \\
\hline \multirow[t]{2}{*}{ Occlusal cavity depth (bitewing radiograph) } & Bravo & 178 & 3.201 & 1.016 & 0.157 & 0.275 \\
\hline & Charlie & 78 & 3.358 & 1.140 & & \\
\hline \multirow[t]{2}{*}{ Mesial cavity (bitewing radiograph) } & Bravo & 178 & 1.140 & 2.095 & 0.206 & 0.476 \\
\hline & Charlie & 78 & 1.346 & 2.129 & & \\
\hline \multirow[t]{2}{*}{ Distal cavity depth (bitewing radiograph) } & Bravo & 178 & 0.986 & 2.035 & 1.347 & 0.000 \\
\hline & Charlie & 78 & 2.333 & 2.461 & & \\
\hline \multirow[t]{2}{*}{ Average depth of MOD cavities (bitewing radiograph) } & Bravo & 178 & 0.831 & 1.219 & 0.631 & 0.000 \\
\hline & Charlie & 78 & 1.463 & 1.230 & & \\
\hline
\end{tabular}

Table 2. Distribution of the sample according to type and class of the restoration.

\begin{tabular}{lllllllll}
\hline Restoration & \multicolumn{2}{c}{ Occlusal } & \multicolumn{2}{c}{ Proximal } & \multicolumn{2}{c}{ MOD } & \multicolumn{2}{c}{ Total } \\
Amalgam & $\mathrm{n}$ & $(\%)$ & $\mathrm{n}$ & $(\%)$ & $\mathrm{n}$ & $(\%)$ & $\mathrm{n}$ & $(\%)$ \\
Resin & 101 & $(48)$ & 86 & $(41)$ & 23 & $(11)$ & 210 & $(100)$ \\
\hline
\end{tabular}

Table 3. Comparison of the results of amalgam and composite restorations in Bravo Group, according to the indicators.

\begin{tabular}{lcc}
\hline Indicator & p-values Amalgam $(n=141)$ & $p$-values Composite $(n=37)$ \\
Mesiodistal dimension & 0.000 & 0.098 \\
Buccolingual/palatal Dimension & 0.442 & 0.388 \\
Average isthmuses & 0.000 & 0.000 \\
Average depth of MOD cavities & 0.000 & 0.000 \\
\hline
\end{tabular}

Table 4. Comparison of the results of amalgam and composite restorations in Charlie Group, according to the indicators.

\begin{tabular}{lcc}
\hline Indicator & $\mathrm{p}$-values Amalgam $(\mathrm{n}=69)$ & $\mathrm{p}$-values Composite $(\mathrm{n}=\mathbf{9})$ \\
Mesiodistal dimension & 0.021 & 0.160 \\
Buccolingual/palatal dimension & 0.006 & 0.510 \\
Average isthmuses & 0.000 & 0.057 \\
Average depth of MOD cavities & 0.000 & 0.013 \\
\hline
\end{tabular}

there was a significant difference in the average of the isthmuses and the depth averages of the MOD cavities. The first indicator was significant for the comparison of types: MOD, proximal occlusal vs. MOD, and proximal occlusal. The second indicator was significant for the comparison of types: occlusal vs. MOD and proximal occlusal, as shown in the table.

Table 6 shows that the four indicators were significant in the comparison of the different types of amalgam restorations in the Charlie group. The mesiodistal dimension was significantly different between the proximal and MOD restorations. The bucco-linguo-palatal dimension is significant in the comparison of proximal vs. occlusal classes. The average of the isthmuses and the average of the depths of the MOD cavities are significant when comparing MOD, proximal occlusal vs. MOD, and proximal-occlusal restorations, as shown in the table. It shows that the significant indicators relative to different types of resin composite 
Table 5.Values of $\mathrm{p}$ with Scheffé Test. Comparison of classes among themselves, according to type of restoration (MOD, proximal and occlusal) and indicators (mesiodistal dimension, buccolingual/palatal dimension, average isthmuses and average depth of MOD cavities) in bitewing radiographs for Bravo group amalgam and composite restorations.

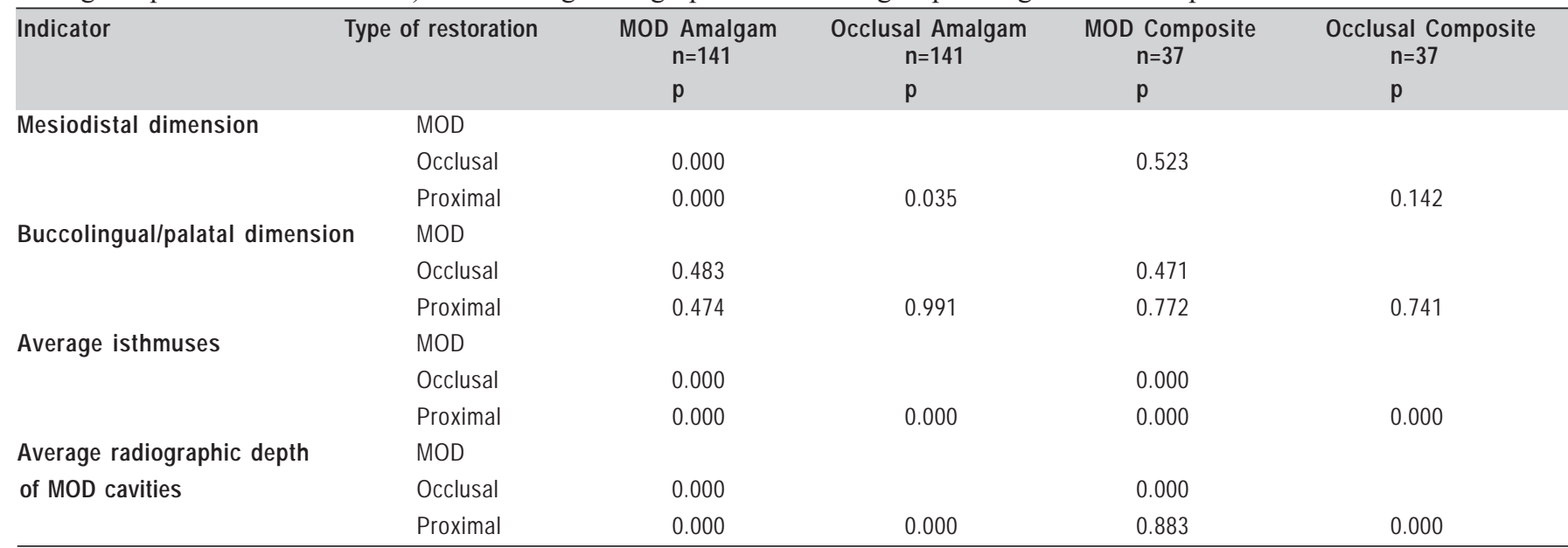

Table 6. Values of $\mathrm{p}$ with Scheffé Test. Comparison of classes among themselves, according to type of restoration (MOD, proximal and occlusal) and indicators (mesiodistal dimension, buccolingual/palatal dimension, average isthmuses and average depth of MOD cavities) in bitewing radiographs for Charlie group amalgam and composite restorations.

\begin{tabular}{|c|c|c|c|c|}
\hline Indicator & Type of restoration & $\begin{array}{c}\text { MOD Amalgam } \\
n=69 \\
p\end{array}$ & $\begin{array}{c}\text { Occlusal Amalgam } \\
n=69 \\
p\end{array}$ & $\begin{array}{c}\text { Occlusal Composite } \\
\qquad \begin{array}{c}n=9 \\
p\end{array}\end{array}$ \\
\hline \multirow[t]{3}{*}{ Mesiodistal dimension } & MOD & & & \\
\hline & Occlusal & 0.427 & & \\
\hline & Proximal & 0.034 & 0.271 & 0.160 \\
\hline \multirow[t]{3}{*}{ Buccolingual/palatal dimension } & MOD & & & \\
\hline & Occlusal & 0.105 & & \\
\hline & Proximal & 0.997 & 0.007 & 0.510 \\
\hline \multirow[t]{3}{*}{ Average Isthmuses } & MOD & & & \\
\hline & Occlusal & 0.000 & & \\
\hline & Proximal & 0.000 & 0.000 & 0.057 \\
\hline \multirow[t]{3}{*}{ Average depth of MOD cavities } & MOD & & & \\
\hline & Occlusal & 0.000 & & \\
\hline & Proximal & 0.000 & 0.000 & 0.013 \\
\hline
\end{tabular}

restorations (proximal vs. occlusal) in the Charlie group were: the average of the isthmuses and the average of the depths of the MOD cavities. Notice that the comparison of the MOD restorations could not be performed between the groups with low $n$ values $(n=2)$.

\section{Discussion}

The pre-determined indicators of the mechanical risk prognosis were chosen from a number of other indicators that are vaguely described in the literature, as these were objectively analyzed within a pool of restorations previously classified as "unsatisfactory" or "failed," meaning that within a medium (Bravo) or short (Charlie) period of time, these restorations required repair or replacement ${ }^{16-21}$. In addition, this study design corresponds to descriptions at a specific time in the long-term life of the restorations (cross-sectional) and not to a follow-up assessment from the origin of the restoration ${ }^{22}$.

In the general comparison of the Bravo and Charlie groups, without considering type and class, the following factors were found to be influential indicators: the mesiodistal dimension, the distal isthmus, the average of the isthmuses, the depth of the distal cavity, and the average depths of the MOD cavities. This finding is consistent with the literature, which states that greater restorations showed increased risk of mechanical failure due to the loss of tissue resistance ${ }^{23-24}$.

It was also demonstrated that the behavior of both groups was similar, with no differences between the Bravo and Charlie restorations. This means that the magnitude of the failure determinant of restoration initial or late damage does not matter because they exhibited similar behavior in terms of prognosis failure by mechanical risk ${ }^{1}$. Therefore, a restoration that presents small mechanical failure, such as 
Bravo restorations, or extensive failure, such as Charlie restorations, should be replaced or repaired promptly. Any mechanical failure, regardless of its magnitude, is a determining factor to carry out the repair or replacement of restoration. With respect to the cavity dimensions, the effects of small restoration on the distribution of stress in a tooth are not significant. However, when the width of the cavity increases, the stress in the distal third of the cervical portion increases rapidly, which is harmful to tooth structure and can easily cause the fracture of the cavity wall. The influence of the size indicators of the distal isthmus, the average of the isthmuses, the distal cavity depth and the average of the depth of the MOD cavities and their relationship with the prognosis of a restoration could be due to the increase in the degree of difficulty for the operator to properly perform a posterior Class II restoration in a distal tooth compared to the one located in a mesial tooth, likely involving variable access, visibility or technique. Table 1 indicates that a restoration with isthmuses greater than $2 \mathrm{~mm}$ and distal cavities greater than $4.5 \mathrm{~mm}$ increased the likelihood of mechanical failure compared to a restoration with smaller dimensions. The results also suggest that increasing the depth of one cavity in a MOD restoration is sufficient to influence the prognosis of the complete restoration.

For the amalgam restorations of the Bravo group, the significant indicators were the mesiodistal dimension, the average of the isthmuses, and the MOD cavities depth. In contrast, for the composite resins from the same group, the average of the isthmuses and the depths of the MOD cavities were significant. In the Charlie group, the four relevant indicators were influential in amalgams, but for resins only the average of the MOD cavities depth was influential. This discrepancy could be due to the heterogeneity of the sample and, therefore, to the low number of posterior composite resin restorations ${ }^{25-26}$. A comparison of the types of restorations (occlusal, proximal and MOD) demonstrated that the only indicator that was significant for all classes, regardless of group and type, was the average of the MOD cavities depth, whose value for 256 restorations was $1.949 \mathrm{~mm}$ with a SD of 1.181 $\mathrm{mm}$. This finding agrees with conclusions described in the literature: changes in the cavity depth also have large effects on the stress distribution and the loads required to fracture the tooth (failure of a restoration) ${ }^{27-28}$. After the deep restoration of a decayed tooth, the maximum stress increases about five times and focuses on the cavity angles. The values of the loads needed to fracture the tooth decrease nearly one-fifth in relation to non-decayed teeth. In addition, deep cavity preparations have been linked to the high cuspal deflection, which predisposes the tooth to fractures ${ }^{10}$. The evaluation of indicators in relation to the prognosis of restorations suggests that for deep MOD carious lesions, a pedagogical protocol must be established, different from the occlusal approach; an alternative might be indirect restoration ${ }^{6,15,25}$.

Furthermore, Class II MOD restorations presented significant indicators more frequently than occlusal and proximal restorations. The indicators were as follows: the average of the isthmuses and the average of the MOD cavities depth for both amalgam and composite resins in both groups. This finding is consistent with the literature, which states that the larger the quantity of restored surfaces and/or amplitude of the isthmus, the higher the possibility of cusp fracture $^{1,25}$

Based on the obtained results, it may be concluded, in contrast to the literature, that the size of the restoration, generally described as "bandwidth," introduces specific indicators in performing a critical evaluation of a restoration. These indicators are the mesiodistal dimension, the size of the distal isthmus, the average of the isthmuses, and the average depth of MOD cavities, which must be evaluated in both models and bitewing radiographs. The depth of the MOD cavity should be assessed with a radiograph and complemented by other indicators obtained from the model (mesiodistal dimension, the size of the distal isthmus and the average of the isthmuses). The dimensions of these indicators influence the prognosis of a restoration.

These indicators should be considered a tool to help decide whether to perform replacement therapy or to repair the affected tooth, with the same material or a combination ${ }^{29-30}$.

In conclusion, the type of restoration (proximal and MOD) is an indicator for the prognosis of mechanical risk for the sample. The restorative material (amalgam or composite resin) for the sample type is not an indicator of the prognosis for mechanical risk. In relation to the design of the cavity preparation, the indicators of the prognosis for mechanical risk assessing a restoration are the mesiodistal dimension, the distal isthmus, the average of the isthmuses, the distal cavity depth, and the average of the MOD cavities depths. The most significant indicator of the risk of mechanical failure is the average of the MOD cavities depth for composite resins. For amalgam, the most significant predictors of the risk of mechanical failure are the mesiodistal dimension, the distal isthmus, the average of the isthmuses, the depth of the distal cavity, and the average of the MOD cavities depth. The depth of the MOD cavity is a significant indicator of the risk of failure for both groups (Bravo and Charlie) and both types (amalgam and composite resin) of restorations. Therefore, indirect restorations techniques should be considered in treating clinical situations that present this indicator. A single clinical assessment does not provide sufficient information to establish the indicators for the risk of mechanical failure of restorations.

\section{References}

1. Dennison JB ,Sarrett DC. Prediction and diagnosis of clinical outcomes affecting restoration margins. J Oral Rehabil. 2012; 39: 301-18.

2. Blum IR, Jagger DC, Wilson NH. Defective dental restorations: to repair or not to repair? Part 1: direct composite restorations. Dent Update. 2011; 38: 78-84

3. Burke FJ, Wilson NH, Cheung SW, Mjör IA. Influence of patient factors on age of restorations at failure and reasons for their placement and replacement. J Dent. 2001; 29: 317-24.

4. Chrysanthakopoulos NA. Placement, replacement and longevity of composite resin-based restorations in permanent teeth in Greece. Int Dent J. $2012 ; 62: 161-6$. 
5. Demarco FF, Correa MB, Cenci MS, Moraes RR, Opdam NJ. Longevity of posterior composite restorations: not only a matter of materials. Dent Mater. 2012; 28: 87-101.

6. Forss $\mathrm{H}$, Widström $\mathrm{E}$. Reasons for restorative therapy and the longevity of restorations in adults. Acta Odontol Scand. 2004; 62: 82-6.

7. Goldstein GR. The longevity of direct and indirect posterior restorations is uncertain and may be affected by a number of dentist-, patient-, and materialrelated factors. J Evid Based Dent Pract. 2010; 10: 30-1.

8. Heintze SD, Rousson V. Clinical effectiveness of direct Class II Restorations - A meta-analysis. J Adhes Dent. 2012; 14: 407-31.

9. Mjör IA, Dahl JE, Moorhead JE. Age of restorations at replacement in permanent teeth in general dental practice. Acta Odontol Scand. 2000; 58 : 97-101.

10. Campos EA, Andrade MF, Porto-Neto ST, Campos LA, Saad JR, Deliberador TM, et al. Cuspal movement related to different bonding techniques using etch-and-rinse and self-etch adhesive systems. Eur J Dent. 2009; 3: 213-8.

11. Palotie U,Vehkalahti MM. Reasons for replacement of restorations: dentists' perceptions. Acta Odontol Scand. 2012; 70: 485-90.

12. Ishikiriama SK, Valeretto TM, Franco EB, Mondelli RF. The influence of "C-factor" and light activation technique on polymerization contraction forces of resin composite. J Appl Oral Sci. 2012; 20: 603-6.

13. Ryge G, Snyder M. Evaluating the clinical quality of restorations. J Am Dent Assoc. 1973; 87: 369-77.

14. Mjör IA ,Ryge G. Comparison of techniques for the evaluation of marginal adaptation of amalgam restorations. Int Dent J. 1981; 31: 1-5.

15. Hickel R, Peschke A, Tyas M, Mjor I, Bayne S, Peters M, et al. FDI World Dental Federation - clinical criteria for the evaluation of direct and indirect restorations. Update and clinical examples. JAdhes Dent. 2010; 12: 259-72.

16. Blum IR, Lynch CD, Schriever A, Heidemann D, Wilson NH. Repair versus replacement of defective composite restorations in dental schools in Germany. Eur J Prosthodont Restor Dent. 2011; 19: 56-61.

17. Fernández EM, Martin JA, Angel PA, Mjör IA, Gordan VV, Moncada GA. Survival rate of sealed, refurbished and repaired defective restorations: 4-year follow-up. Braz Dent J. 2011; 22: 134-9.

18. Gordan VV, Riley JL, 3rd, Blaser PK, Mondragon E, Garvan CW, Mjor IA. Alternative treatments to replacement of defective amalgam restorations: results of a seven-year clinical study. J Am Dent Assoc. 2011; 142: 842-9.

19. Moncada G, Martin J, Fernández E, Hempel MC, Mjör IA, Gordan VV. Sealing, refurbishment and repair of Class I and Class II defective restorations: a three-year clinical trial. J Am Dent Assoc. 2009; 140: 425-32.

20. Moncada G, Fernández E, Martín J, Arancibia C, Mjör IA ,Gordan VV. Increasing the longevity of restorations by minimal intervention: a twoyear clinical trial. Oper Dent. 2008; 33: 258-64.

21. Moncada GC, Martin J, Fernandez E, Vildosola PG, Caamano C, Caro $\mathrm{MJ}$, et al. Alternative treatments for resin-based composite and amalgam restorations with marginal defects: a 12-month clinical trial. Gen Dent. 2006; 54: 314-8.

22. Knibbs PJ. Methods of clinical evaluation of dental restorative materials. J Oral Rehabil. 1997; 24: 109-23.

23. Mjör IA, Moorhead JE, Dahl JE. Reasons for replacement of restorations in permanent teeth in general dental practice. Int Dent J. 2000; 50: 361-6.

24. Asmussen $E$,Peutzfeldt $A$. Class I and Class II restorations of resin composite: an FE analysis of the influence of modulus of elasticity on stresses generated by occlusal loading. Dent Mater. 2008; 24: 600-5.

25. Deliperi S. Functional and aesthetic guidelines for stress-reduced direct posterior composite restorations. Oper Dent. 2012; 37: 425-31.

26. Forss $\mathrm{H}$,Widström $\mathrm{E}$. From amalgam to composite: selection of restorative materials and restoration longevity in Finland. Acta Odontol Scand. 2001; 59: $57-62$.

27. Mjör IA, Um CM. Survey of amalgam and composite restorations in Korea. Int Dent J. 1993; 43: 311-6.
28. Mjör IA, Gordan VV. Failure, repair, refurbishing and longevity of restorations. Oper Dent. 2002; 27: 528-34.

29. Tolidis K, Boutsiouki C, Gerasimou P. Microleakage in combined amalgam/ composite resin restorations in MOD cavities. Braz J Oral Sci. 2013; 12: 100-4.

30. Hickel R, Brushaver K, llie N. Repair of restorations-criteria for decision making and clinical recommendations. Dent Mater. 2013; 29: 28-50. 